\title{
Hubungan Kualitas Tidur dengan Nyeri Kepala Primer pada Masyarakat Daerah Pesisir Desa Nusalaut, Ambon
}

\author{
Priskilla Rosse Gratia Habel $^{1}$, Parningotan Yosi Silalahi ${ }^{1}$, Yuniasih Taihuttu ${ }^{1}$ \\ 1.Fakultas Kedokteran Universitas Pattimura, Ambon \\ Korespondensi : $\underline{\text { ikahabel212@gmail.com }}$
}

\begin{abstract}
ABSTRAK
Pendahuluan: gangguan tidur dan nyeri kepala primer (NKP) merupakan penyakit yang sering dijumpai pada masyarakat dan secara teori berhubungan secara resiprokal. Beberapa faktor yang berhubungan dengan timbulnya nyeri kepala pimer antara lain kualitas tidur yang buruk, kelelahan, perubahan suhu. Kelompok masyarakat yang rentan terkena dampak gangguan kualitas tidur adalah masyarakat pesisir. Namun pada daerah Nusalaut penelitian ini belum pernah dilakukan, padahal daerah ini merupakan area pesisir yang kelompok pekerja utamanya adalah pekerja di laut. Tujuan penelitian ini adalah untuk mencari hubungan antara kualitas tidur dan nyeri kepala primer daerah ini.

Metode: pengumpulan data dilakukan dengan menggunakan pendekatan cross sectional pada masyarakat di Nusalaut yang berjumlah 190 orang dengan teknik cluster random sampling. Kualitas tidur dinilai dengan The Pitssburg Sleep Quality Index (PSQI) sedangkan nyeri kepala primer dinilai dengan kuesioner HO K-H dan Ong BK-C. Analisis deksriptif digunakan untuk menentukan karakteristik subjek sedangkan korelasi antara kualitas tidur dengan nyeri kepala primer diperoleh melalui uji korelasi Spearman.

Hasil: terdapat hubungan yang bermakna antara jenis kelamin, usia dan jenis pekerjaan dengan kualitas tidur dan nyeri kepala primer. Antara kualitas tidur dan nyeri kepala primer tidak memiliki hubungan yang bermakna dengan korelasi yang sangat lemah $(\mathrm{p}=0,323)$.

Kesimpulan: tidak ada hubungan yang bermakna antara kualitas tidur dengan nyeri kepala primer pada masyarakat pesisir desa Nusalaut.
\end{abstract}

Kata Kunci: kualitas tidur; nyeri kepala primer; masyarakat pesisir

\begin{abstract}
Introduction: Sleep disorders and primary headaches (NKP) is a common disease in the community and both relate reciprocally. Some of the factors associated with the onset of primary headache include poor sleep quality, fatigue, change in temperature. Coastal communities are groups of people who have high risk factors for developing such disorders. This study aimed to explore the relationship between quality of sleep and primary headaches in coastal communities in Nusalaut which never held backward. Methods: Data was collected by using a cross sectional study conducted in communities in Nusalaut amounted to 190 people with data retrieval techniques cluster random sampling. Quality of sleep was assessed by The Pitssburg Sleep Quality Index (PSQI), while primary headache was assessed by questionnaire and Ong BK KH HO-C. Descriptive analysis to determine the characteristics of the subject while the correlation between sleep quality with primary headache is done by Spearman correlation test.

Results: The results showed there is a significant association between factors such as gender, age and type of work with quality bedding and primary headaches while between quality of sleep and primary headaches do not have a meaningful correlation with the strength of the correlation was very weak $(p=0.323)$.
\end{abstract}


Habel et. al., Hubungan kualitas tidur dengan nyeri kepala primer pada masyarakat daerah pesisir desa nusalaut, Ambon

Conclusion: there was no significant correlation between quality of sleep and primary headaches.

Keywords: quality of sleep; headache primer; coastal communities

\section{PENDAHULUAN}

Nyeri kepala atau cephalgia merupakan salah satu gangguan sistem saraf yang paling umum dialami oleh masyarakat. Cephalgia merupakan suatu sensasi tidak nyaman yang dirasakan pada daerah kepala yang meliputi daerah wajah dan leher ${ }^{1,2,3}$. Nyeri kepala yang terjadi dapat menimbulkan dampak-dampak negatif bagi masyarakat jika tidak diatasi, yaitu menurunkan kualitas hidup, menurunkan kemampuan melakukan aktifitas dan menambah beban sosial-ekonomi masyarakat ${ }^{4,5,6}$. Berdasarkan penelitian yang dilakukan oleh Stovner ${ }^{3}$ di Norwegia pada tahun 2007 persentase prevalensi nyeri kepala sebesar 46\%. Data lain menurut World Health Organization (WHO) pada tahun 2012, sekitar $90 \%$ populasi dewasa di dunia setidaknya pernah mengalami satu kali nyeri kepala dalam satu tahun. ${ }^{7}$

Faktor-faktor risiko yang menyebabkan timbulnya nyeri kepala primer yaitu faktor usia remaja,dewasa dan lanjut usia, faktor depresi, kecemasan, kelelahan, perubahan cuaca, serta gangguan tidur. ${ }^{6,7,8}$ Salah satu faktor risiko nyeri kepala, yaitu adanya gangguan tidur. Kelebihan atau kekurangan tidur memberi dampak buruk bagi kesehatan. $^{8,9,10}$ Frekuensi nyeri kepala, intensitas nyeri kepala, dan onset nyeri kepala memiliki hubungan yang signifikan dengan kejadian gangguan tidur spesifik, termasuk mimpi buruk, sulit untuk tertidur, terbangun terlalu pagi, dan kualitas tidur yang buruk ${ }^{11}$. Hal ini diakibatkan oleh karena nyeri kepala yang terjadi menyebabkan orang tetap terjaga yang mencegah tidur dan mengubah arsitektur tidur menjadi lebih terfragmentasi yang akhirnya menyebabkan durasi tidur menjadi lebih singkat dan mengantuk berlebihan pada siang hari sehingga menyebabkan aktivitas dan daya konsentrasi yang menurun. Nyeri kepala dan gangguan tidur dapat terjadi karena dipicu oleh perubahan neurotransmitter seperti serotonin dan melatonin dan gangguan pada irama sirkadian ${ }^{12,13}$.

Faktor penyebab gangguan tidur dan nyeri kepala primer pada daerah pesisir sangat bervariasi yaitu kelelahan, perubahan cuaca, kondisi stress, beban kerja yang tinggi, mengkonsumsi makanan yang tidak sehat dan perubahan waktu tidur ${ }^{13,14}$. Selain itu dilaporkan bahwa terdapat hubungan antara aktivitas fisik dan kelelahan kerja pada nelayan dengan tingkat aktivitas sedang sebanyak $62 \%$ yang dapat menyebabkan terjadinya berbagai masalah kesehatan salah satunya yaitu nyeri kepala ${ }^{15}$. Penelitian lain yang dilakukan oleh Andruskiene et al pada tahun 2016 menyatakan bahwa terdapat hubungan antara populasi yang bekerja di laut dengan menurunnya kualitas tidur yaitu sebanyak $45 \%{ }^{14}$.

Pulau Nusalaut adalah sebuah pulau kecil diantara enam gugusan pulau di wilayah Maluku dan merupakan salah satu pulau dengan wilayah pesisir yang luas karena letaknya yang berada di tengah laut luas yakni laut banda. Mata pencaharian penduduk Pulau Nusalaut sangat bervariasi diantaranya nelayan, petani juga berbagai jenis pekerjaan lainnya seperti ibu rumah tangga (IRT) dan wiraswasta. Berbagai jenis pekerjaan tersebut memiliki risiko untuk mengalami kelelahan akibat dari pekerjaan yang dilakukan yang merupakan faktor risiko gangguan tidur dan nyeri kepala primer. 
Habel et. al., Hubungan kualitas tidur dengan nyeri kepala primer pada masyarakat daerah pesisir desa nusalaut, Ambon

\section{METODE}

Penelitian ini merupakan penelitian analitik korelatif dengan pendekatan crosssectional. Populasi terjangkau dalam penelitian ini mencakup masyarakat desa Nusalaut Kabupaten Maluku Tengah yang berusia 18-65 tahun dan pernah mengalami nyeri kepala dan gangguan tidur sebelumnya. Responden yang sedang mengkonsumsi obatobat penenang seperti antidepresan, yang sedang menderita penyakit yang mempengaruhi tidur seperti depresi, asma, trauma kapitis, stroke, memiliki kadar kolestrol >200 $\mathrm{mg} / \mathrm{dl}$ dan sedang mengkonsumsi obat-obat penyebab sakit kepala seperti obat kontrasepsi, ibuprofen, parasetamol, aspirin dan kodein dalam jangka panjang tidak diikutsertakan dalam penelitian ini.

Teknik pengambilan sampel yang digunakan adalah cluster random sampling. Besar sampel minimal dari penelitian ini adalah 190 orang. Instrumen yang digunakan adalah kuesioner Pittsburgh Sleep Quality Index (PSQI) untuk menilai kualitas tidur selama satu bulan terakhir dan untuk membedakan tidur yang baik dan buruk. Domain yang diukur termasuk kualitas tidur, subjektif, latensi tidur, durasi tidur, efisiensi tidur, gangguan tidur, pemakaian obat, dan gangguan melaksanakan kegiatan sehari-hari ${ }^{16}$. Untuk mendiagnosa nyeri kepala digunakan kuesioner Ho dan Ong berdasarkan kriteria diagnostik oleh HIS dan Konsensus Nasional IV PERDOSSI $2013^{1,2}$.

Analisis data dilakukan dengan software Microsoft Excel dan Software Statistic Packages for Social Sciences (SPSS) for windows SPSS versi 16.0. Analisis yang digunakan yaitu analisis univariat untuk menjelaskan prevalensi kualitas tidur dan prevalensi nyeri kepala primer dan analisis bivariat untuk menilai dan menganalisis hubungan antara kualitas tidur dengan nyeri kepala primer. Uji hipotesis yang digunakan adalah uji Chi Square.

Penelitian ini telah mendapat persetujuan komite etik dengan nomor 216/FK-KOM.ETIK/VIII/2018.

\section{HASIL}

\section{Karakteristik Responden}

Hasil penelitian menunjukkan bahwa responden yang berjenis kelamin perempuan lebih banyak dibandingkan dengan laki-laki, berturut-turut $72,11 \%$ dan laki-laki $27,89 \%$. Bila ditinjau berdasarkan usia, persentase tertinggi responden berada dalam kelompok usia 18-35 tahun $(48,42 \%)$ dan terendah berada pada kelompok usia $>56$ tahun $(4,74 \%)$. Sedangkan, berdasarkan pekerjaan, ibu rumah tangga merupakan responden terbanyak $(51,5 \%)$ dan Polisi/TNI/tidak bekerja sebesar adalah jenis pekerjaan yang paling sedikit diantara responden $(2,11 \%)$.

\section{Proporsi Kualitas Tidur}

Berdasarkan gambar 1 terlihat bahwa total proporsi kualitas tidur baik sebesar $54,74 \%$, kualitas tidur sedang dengan persentase sebesar $42,63 \%$ dan kualitas tidur buruk sebesar $2,63 \%$.

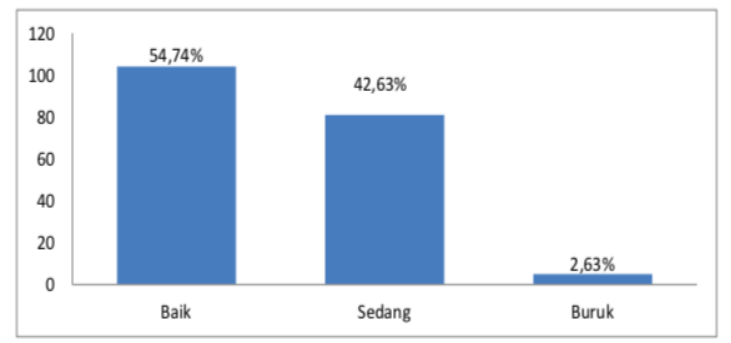

Gambar 1. Proporsi kualitas tidur

\section{Distribusi Kualitas Tidur berdasarkan Jenis Kelamin, Usia dan Pekerjaan}

Pada distribusi frekuensi kualitas tidur responden menurut jenis kelamin ditemukan bahwa persentase perempuan lebih tinggi daripada laki-laki yaitu sebesar $72,11 \%$. Distribusi kualitas tidur baik berdasarkan jenis kelamin tertinggi pada jenis kelamin 
Habel et. al., Hubungan kualitas tidur dengan nyeri kepala primer pada masyarakat daerah pesisir desa nusalaut, Ambon

perempuan dengan persentase sebesar $72,11 \%$ $(\mathrm{n}=75) \quad$ sedangkan sebanyak $60 \% \quad(\mathrm{n}=3)$ kualitas tidur buruk juga ditemukan pada perempuan.

Menurut usia, kualitas tidur baik tertinggi pada kelompok usia 18-35 tahun dengan persentase sebesar $48,42 \%$ dan terendah didapatkan pada kelompok usia $>56$ tahun dengan persentase sebesar 4,74\%.

Ditinjau berdasarkan jenis pekerjaan ditemukan kualitas tidur baik tertinggi pada jenis pekerjaan ibu rumah tangga (IRT) sebanyak 48,08\% sedangkan distribusi kualitas tidur sedang tertinggi juga pada jenis pekerjaan IRT $(56,79 \%)$ dan kualitas tidur buruk tertinggi pada jenis pekerjaan IRT dan Nelayan sebanyak 2 responden pada jenis pekerjaan tersebut (40\%). Distribusi di atas dihitung berdasarkan jenis pekerjaan responden dengan jumlah tingkatan kualitas tidur.

\section{Proporsi Nyeri Kepala Primer}

Berdasarkan gambar 2 dapat diketahui bahwa persentase tertinggi nyeri kepala primer tipe TTH merupakan nyeri kepala yang paling sering dialami dengan persentase sebesar 80,53\%, sedangkan nyeri kepala primer tipe chronic tension-type headache (CTH) tidak ditemukan (0\%).

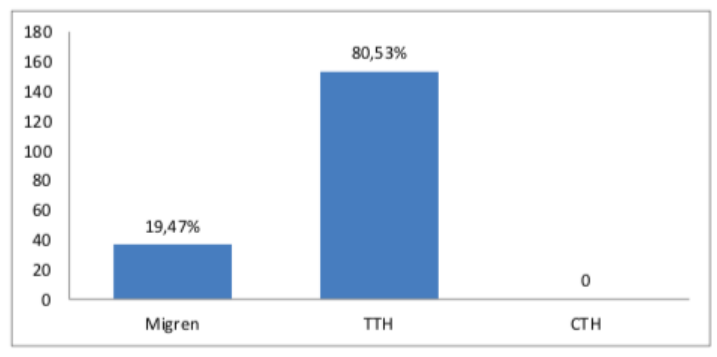

Gambar 2. Nyeri kepala primer

\section{Distribusi Nyeri Kepala Primer Berdasarkan Jenis Kelamin, Usia dan Pekerjaan}

Berdasarkan jenis kelamin persentase nyeri kepala primer tertinggi didapatkan pada kelompok perempuan $(72,11 \%)$. Menurut usia responden, didapatkan persentase tertinggi terjadi pada kelompok usia 18-35 tahun dengan persentase sebesar $48,42 \%$ sedangkan persentase terendah berada pada responden dengan kelompok usia $>56$ tahun $(4,74 \%)$.

Ditinjau berdasarkan jenis pekerjaan, pada nyeri kepala primer tipe migren ditemukan distribusi tertinggi pada kelompok pekerjaan IRT sebanyak 21 responden $(56,76 \%)$ dan terendah pada jenis pekerjaan nelayan dan tidak bekerja sebanyak $0 \%$. Sedangkan, pada nyeri kepala primer tipe TTH didapatkan distribusi tertinggi ju ga pada kelompok jenis pekerjaan IRT sebanyak 77 responden $(50,33 \%)$ dan distribusi terendah pada kelompok jenis pekerjaan honorer dan Polisi/TNI sebanyak 2 responden $(1,31 \%)$ dan pada nyeri kepala primer tipe CTH tidak ditemukan pada penelitian ini.

\section{Hubungan Kualitas Tidur dan Nyeri Kepala Primer}

Tabel 1. Distribusi kualitas tidur dan nyeri kepala

\begin{tabular}{|c|c|c|c|}
\hline \multirow{2}{*}{$\begin{array}{c}\text { Kualitas } \\
\text { Tidur }\end{array}$} & \multicolumn{3}{|c|}{ Nyeri Kepala } \\
\cline { 2 - 4 } & Migren & TTH & Total \\
\hline Baik & 17 & 87 & 104 \\
\hline Sedang & 20 & 61 & 81 \\
\hline Buruk & 0 & 5 & 5 \\
\hline Total & 37 & 153 & 190 \\
\hline
\end{tabular}

Terlihat pada tabel 1 distribusi kualitas tidur dan nyeri kepala primer pada desa di Pulau Nusalaut yaitu responden dengan kualitas tidur baik sebanyak 104 responden menderita nyeri kepala primer tipe migren sebanyak 17 responden dan nyeri kepala primer tipe TTH sebanyak 87 responden. Sedangkan responden dengan kualitas tidur sedang sebanyak 81 responden menderita nyeri kepala primer tipe migren sebanyak 20 
Habel et. al., Hubungan kualitas tidur dengan nyeri kepala primer pada masyarakat daerah pesisir desa nusalaut, Ambon

responden dan nyeri kepala tipe TTH sebanyak 61 orang. Responden dengan kualitas tidur buruk sebanyak 5 orang menderita nyeri kepala primer tipe TTH sebanyak 5 responden.

Hasil uji statistik menggunakan korelasi uji spearman diperoleh $p$ value $=0,323$ (p>0,005). Hal ini menunjukan bahwa korelasi antara skor kualitas tidur dan nyeri kepala primer tidak bermakna. Sedangkan arah hubungan adalah negatif karena nilai $r=0,072$.

\section{PEMBAHASAN}

\section{Kualitas Tidur}

Tidur memainkan peranan penting dalam kehidupan masyarakat. Selama masa dewasa, pola tidur secara umum mengalami keterlambatan pada waktu memulai tidur tetapi orang dewasa dituntut harus bangun lebih cepat untuk memulai aktifitas sosial karena pada usia dewasa seseorang sedang berada di puncak aktif aktifitas sosial. Keterlambatan fase tidur merupakan akibat dari keterlambatan jam biologis irama sirkadian pada usia dewasa dan adanya faktorfaktor lain yang mempengaruhi misalnya suhu yang berubah-ubah dan aktivitas di sekitar lingkungannya ${ }^{17,18}$.

Hasil penelitian ini melaporkan bahwa responden laki-laki memiliki kualitas tidur yang lebih baik dibandingkan dengan responden perempuan. Meskipun tidak lebih tinggi nilainya dibandingkan perempuan, namun ditemukan bahwa tidak ada laki-laki yang memiliki kualitas tidur buruk. Kimura tahun 2005 menyatakan bahwa kualitas tidur yang buruk pada perempuan disebabkan oleh karena terjadi penurunan hormon progesteron dan estrogen yang mempunyai reseptor di hipotalamus, sehingga memiliki andil pada irama sirkadian dan pola tidur secara langsung. Kondisi psikologis, meningkatnya kecemasan, gelisah dan emosi sering tidak terkontrol pada perempuan akibat penurunan hormon estrogen yang bisa menyebabkan gangguan tidur ${ }^{19}$.

Jenis kelamin perempuan juga berhubungan dengan kualitas tidur seseorang, tetapi secara statistik tidak ditemukan adanya hubungan antara jenis kelamin responden dengan kualitas tidur, namun terlihat kecenderungan bahwa perempuan memiliki distribusi gangguan tidur yang lebih besar karena cenderung untuk lebih menunda waktu mereka untuk istirahat malam dan juga bangun lebih awal ${ }^{20}$.

Dalam penelitian ini dilaporkan bahwa kelompok umur $>56$ tahun memiliki kualitas tidur yang buruk. Hal ini dikarenakan terjadinya proses degenerasi pada kelompok usia tersebut sehingga kurang efektifnya waktu tidur, waktu tidur yang semakin berkurang dan tidak tercapainya kualitas tidur yang adekuat ${ }^{21}$.

Jenis pekerjaan yang ditemukan pada penelitian ini menunjukan bahwa IRT dan nelayan memiliki kualitas tidur yang buruk dibandingkan dengan pekerjaan lainnya. Kelompok pekerjaan IRT mempunyai tugas dan tanggung jawab yang berat. Mereka harus bangun pagi-pagi dan melakukan pekerjaan rumah tangga dan melakukan pekerjaan lainnya sampai malam ${ }^{22}$. Sedangkan kelompok pekerjaan sebagai nelayan memiliki kualitas tidur yang buruk disebabkan oleh aktivitas bekerja yang cenderung dilakukan di malam hari dan berada di lautan terbuka dalam waktu yang cukup lama serta perubahan cuaca dan suhu tubuh nelayan yang berubah-ubah sehingga menyebabkan kesulitan untuk tidur serta faktor lainnya yaitu kelelahan pada saat bekerja karena menunggu dan menarik tangkapan setiap saat dalam keadaan terjaga sehingga menyebabkan terjadi gangguan tidur ${ }^{13,14}$.

\section{Nyeri Kepala Primer}

Pada penelitian ini tingkat prevalensi nyeri kepala primer tertinggi pada nyeri 
Habel et. al., Hubungan kualitas tidur dengan nyeri kepala primer pada masyarakat daerah pesisir desa nusalaut, Ambon

kepala primer tipe TTH yaitu sebanyak 80,53\%. Sjahrir pada tahun 2008 melaporkan bahwa prevalensi pasien dengan episodic tension-type headache sebesar $31 \%^{2,7}$. Kharisma pada tahun 2017 menyatakan bahwa TTH merupakan nyeri kepala primer yang paling sering terjadi di masyarakat ${ }^{23}$.

Hasil penelitian distribusi nyeri kepala primer berdasarkan jenis kelamin didapatkan bahwa jenis kelamin perempuan lebih sering mengalami nyeri kepala dengan persentase sebesar $72,11 \%$. Penelitian sebelumnya yang dilakukan oleh Fendrik et al. tahun 2007 menyatakan bahwa prevalensi NKP pada perempuan secara bermakna lebih tinggi dari pada laki-laki. Perubahan hormonal diperkirakan menjadi salah satu faktor penyebabnya. Adanya perubahan kadar estradiol pada saat fase menstruasi dari siklus ovarium berhubungan dengan munculnya beberapa gangguan neurologi misalnya pada penderita migren yang diakibatkan karena estradiol bekerja dengan meningkatkan aktivitas sel-sel saraf sehingga akibat penurunan kadar estradiol yang cepat selama fase menstruasi memberikan reaksi simpatikotonik terhadap ambang rangsang sehingga rangsangan sensibel berkembang menjadi nyeri. Selain itu menurunkan kadar estrogen menyebabkan penurunan serotonin dan penurunan kadar endorphin sehingga menyebabkan munculnya migren ${ }^{23}$.

Berdasarkan hasil penelitian ini didapatkan bahwa pada kelompok usia 1835 tahun dan kelompok usia 36-55 tahun memiliki frekuensi terjadinya nyeri kepala yang tinggi yaitu sebesar $48,42 \%$ dan $46,84 \%$ menderita nyeri kepala primer. Data ini sesuai dengan penelitian yang dilakukan oleh Kharisma pada tahun 2015 yang menyatakan bahwa nyeri kepala primer lebih sering terjadi pada usia dewasa dengan onset awal terjadi pada usia $<20$ tahun dan puncak pada usia 20 dan 50 tahun dan lebih sering terjadi pada wanita dewasa dengan rasio wanita dan pria 4:3. Hal ini disebabkan oleh karena tingkat aktivitas sosial yang tinggi dari kelompok usia tersebut ${ }^{22,24}$. Hasil penelitian ini melaporkan bahwa frekuensi nyeri kepala primer berdasarkan jenis pekerjaan yang dilakukan responden ditemukan bahwa terdapat 3 jenis pekerjaan yang lebih sering mengalami nyeri kepala primer yaitu IRT dengan persentase 51,58\%, wiraswasta $14,74 \%$ dan nelayan sebanyak $9,47 \%$. Hal ini sesuai dengan penelitian yang dilakukan sebelumnya yang menyatakan bahwa kelompok pekerjaan tersebut memiliki berbagai faktor risiko pencetus nyeri kepala primer yaitu beban langsung pada saat bekerja, waktu kerja yang tidak produktif baik pada karyawan maupun pekerja rumah tangga. Sedangkan pada nelayan postur tubuh yang buruk pada saat bekerja dan perubahan cuaca. Hal ini disebabkan oleh karena gaya bekerja pada saat nelayan bekerja di lautan terbuka dalam waktu yang cukup lama sehingga posisi pada saat bekerja sering tidak menentu dan berada dalam posisi yang tidak ergonomis akibat kecilnya perahu yang digunakan atau posisi pada saat harus menebarkan jala, menunggu dan menarik jala kembali. Selain itu perubahan cuaca mengakibatkan suhu tubuh pada nelayan sering berubah-ubah karena jam kerja yang berisiko dalam jangka waktu melaut dari malam hingga pagi hari serta udara laut pada saat nelayan bekerja merupakan faktor risiko terkena nyeri kepala primer ${ }^{25,26,27}$.

\section{Hubungan Kualitas Tidur dan Nyeri Kepala Primer}

Hasil penelitian ini menunjukkan tidak ada hubungan antara kualitas tidur dan nyeri kepala primer pada masyarakat pesisir di pulau Nusalaut. Hal ini terlihat dari hasil penelitian yaitu responden dengan kualitas tidur baik dan sedang juga dapat mengalami berbagai tipe nyeri kepala primer.

Andruskiene et al. pada tahun 2016 menyatakan bahwa terdapat hubungan yang 
Habel et. al., Hubungan kualitas tidur dengan nyeri kepala primer pada masyarakat daerah pesisir desa nusalaut, Ambon

kuat antara kualitas tidur dan nyeri kepala primer dimana semakin buruk kualitas tidur seseorang semakin berisiko orang tersebut untuk menderita nyeri kepala primer. Nyeri kepala primer menyebabkan seseorang tetap terjaga yang mencegah tidur dan mengubah arsitektur tidur menjadi lebih terfragmentasi yang akhirnya menyebabkan durasi tidur menjadi lebih singkat dan mengantuk berlebihan pada siang hari ${ }^{12,13}$.

Hubungan antara gangguan tidur dan NKP secara umum memiliki dasar struktur neuroanatomi dan mekanisme neurofisiologi yang sama, meliputi hipotalamus, serotonin dan melatonin. Hipotalamus posterior bekerja sebagai pusat pengaturan utama fungsi otonom sentral, sehingga apabila terjadi perubahan pada fungsi homeostatik akan menyebabkan perubahan pada control nyeri. Hipotalamus posterior juga memiliki hubungan yang penting dengan sistem modulasi nyeri, menerima input dari korteks singulatus anterior, nuklues septal lateral, nukleus preoptik, nuklues ventromedial dan lateral talamus, serta PAG. Hipotalamus posterior penting dengan sistem modulasi nyeri, menerima input dari korteks singulatus anterior, nuklues septal lateral, nukleus preoptik, nuklues ventromedial dan lateral talamus, serta PAG. Hipotalamus posterior kemudian memproyeksikan serabutnya ke subtalamus, amigdala, dasar dari otak depan, regio limbik dan nukleus trigeminal kaudalis. Hipotalamus menjelaskan hubungan anatomikal antara timbulnya NKP dengan gangguan tidur. Selain itu, aktivasi ARAS di batang otak menyebabkan kita terjaga dan adanya pengaruh neurotransmiter kortikal seperti epinefrin, dopamin dan asetilkolin mempertahankan kewaspadaan selama terjaga. Tidur fase non rapid eye movement (NREM) dikontrol oleh pengaruh neuron-neuron gamma-aminobutyric acid GABA di basal forebrain. Generator fase rapid eye movement (REM) terletak di daerah tegmentum pontin dorsolateral. Fase rapid eye movement diinisiasi oleh pelepasan asetilkolin yang diaktivasi oleh neuron pontin tersebut ${ }^{12,13}$.

Nyeri kepala primer yang seringkali dihubungkan dengan tidur pada berbagai penelitian adalah migren. Serangan migren pada fase prodromal diawali oleh gangguan fungsional neuronal pada hipotalamus. Gangguan periodisitas sentral di hipotalamus ini dapat dilihat sesuai dengan periodisitas serangan migren dan adanya perubahan emosional oleh mekanisme jalur sistem limbik yang berhubungan dengan hipotalamus. Gangguan fisiologi bioritmik hipotalamus seperti perubahan hormonal, gangguan tidur dan perubahan nafsu makan merupakan beberapa faktor yang sering memicu serangan migren $^{5,28}$

Penelitian yang pernah dilakukan sebelumnya oleh Peres et. al pada tahun 2006 menyatakan bahwa terdapat hubungan yang lemah antara kualitas tidur dan nyeri kepala primer dimana responden dengan kualitas tidur baik juga mengalami nyeri kepala primer yang tinggi hal ini disebabkan oleh karena disfungsi melatoninserta gangguan ritme sirkadian oleh disfungsi nucleus suprachiasmatic hipotalamus yang mendasari patofisiologi kedua fenomena yang saling mempengaruhi kualitas tidur dan nyeri kepala primer. Selain itu melatonin memiliki peranan dalam regulasi serebrovaskular dengan meningkatkan efek vasokonstriksi dari noradrenalin. Melatonin diproduksi pada saat tidur di malam hari, sehingga orang-orang yang memiliki kualitas tidur yang baik, dapat memiliki kadar melatonin yang lebih tinggi hal ini menyebabkan intensitas dan frekuensi nyeri kepala pada orang yang memiliki kualitas tidur baik menjadi rendah sehingga dapat terkena gangguan nyeri kepala ${ }^{28}$.

Keterbatasan dalam penelitian ini ialah jumlah responden IRT lebih mendominasi responden yang terpilih. 
Habel et. al., Hubungan kualitas tidur dengan nyeri kepala primer pada masyarakat daerah pesisir desa nusalaut, Ambon

Selain itu, tidak adanya informasi yang cukup tentang responden yang memiliki kualitas tidur yang buruk seperti terbangun di tengah malam dengan aktivitas yang dilakukan setelah terbangun.

\section{KESIMPULAN}

Adanya hubungan yang tidak bermakna antara kualitas tidur dan nyeri kepala primer $\mathrm{p}=0,323$ dengan kekuatan korelasi yang sangat lemah dan arah hubungan yang negatif $r=0,072$.

\section{DAFTAR PUSTAKA}

1. Headache Classification Subcommittee of the International Headache Society: The International Classification of Headache Disorders, 2nd edn. Cephalalgia 2004;24(Supp 1):1-150.

2. Kelompok Studi Nyeri Kepala PERDOSSI. Diagnostik dan penatalaksanaan nyeri kepala. Surabaya: Airlangga University Press;2011.

3. Stovner L. Hagen K. Jensen R. et al. The global burden of headache: a documentation of headache prevalence and disability worldwide. Cephalalgia 2007;27:193-210.

4. Rains JC, Poceta JS, Penzien DB. Sleep and headaches. Curr Neurol Neurosci Rep 8:167-175; 2008

5. Brennan KC, Charles A. Sleep and Headache. Seminars in Neurology;2009.

6. Alberti A . Headache and sleep. Sleep Med Rev 2006 ; 10:431- 437.

7. World Health Organization. Sleep and cephalgia WHO; WHO: 2012.

8. Ganong AC, Hall JE. Buku ajar fisiologi kedokteran. Ed 11. Jakarta: EGC;2008.

9. Dodick DW, Eross EJ, Parish JM, Silber M. Clinical, anatomical, and physiologic relationship between sleep and headache. Headache. 2008; 43:282-29210. Jennum P, Jensen $R$. Sleep and headache. Sleep Med Rev 6:471479;2002.

10.Jennum $P$, Jensen $R$. Sleep and headache. Sleep Med Rev 6:471479;2002

11.Lyngberg AC, Rasmussen BK, Jorgensen $\mathrm{T}$, Jensen $\mathrm{R}$ : Has the prevalence of migraine and tension-type headache changed over a 12-year period? A Danish population survey. Eur $\mathrm{J}$ Epidemiol 2005;20:243-9.

12.Boardman HF, Thomas E , Millson DS, Croft PR. Psychological, sleep, lifestyle, and comorbid associations with headache. Headache. 2005; 45: 657-669.

13.Sumampouw OJ, Andarini S, Sriwahyuni E, Nelwan EJ. Eksplorasi masalah kesehatan masyarakat di daerah pesisir kota manado. Manado; Fakultas Kesehatan Masyarakat Unsrat; 2015.

14.Andruskiene J, Barseviciene S, Varoneckas G. Poor sleep, anxiety, depression and other occupational health risks in seafaring population. Lithuania; The International Journal on Marine Navigation and Safety of Sea Transportation; 2016.

15.Direktorat Pendayagunaan Pulau-pulau Kecil. Kementerian Kelautan dan Perikanan. Jakarta ; 2012.

16.Orhan, Ozlem F, Tuncel et.al. Relationship between sleep quality and depression amon elderly nursing home residents in turkey. Proquest Psychology Journals. $2012 ; 16: 1059-1067$.

17.Santrock J W. Psikologi Pendidikan. Ed 2. Jakarta; Kencana : 2007

18.Sivertsen B, Pallesen S, Stormark K, Lundervold A, Hysing M. Delayed Phase Syndrome in Adolescents: Prevalence and Correlates in a Large Population Base Study: BMC Public Health; 2013

19.Kimura M. Gender Specific Sleep Regulation. Japan Clinical Journal Vol 2(3); 2005. 
Habel et. al., Hubungan kualitas tidur dengan nyeri kepala primer pada masyarakat daerah pesisir desa nusalaut, Ambon

20.Patten Et. Al. Teenage attitudes and Practices Survey, American Heart Association,:Inc Journal Circulation: 2010

21.Chasanah N. Hubungan Kualitas tidur dengan kualitas hidup pada lansia di kelurahan karangasem kecamatan laweyan Surakarta. Skripsi; Universitas Muhammadiyah: 2017

22.Febrianti $\mathrm{N} \quad \mathrm{H}$. Hubungan dukungan keluarga dengan kejadian insomnia pada lanjia di dusun krodan sleman Yogjakarta. Skripsi: STIKES Yogyakarta: 2015

23. Kharisma Y. Tinjuan umum penyakit nyeri kepala. Jurnal Kesehatan Indonesia. Bandung; Fakultas kedokteran universitas islam bandung: 2017

24.Fendrich K, Vennemann M, Pfaffenrath M, Evers S. Headache Prevalence Among Adolescents. Germany; The German DMKG Headache Study Cephalgia: 2007

25.Deborah S, Katherine C, Herdon. Headache Disorder Pharmacoterapy a pathophysiologic approach. Ed7. McGraw Hill ; 2008.

26. Khairunisa S. Hubungan tingkat stress dengan nyeri kepala. Skripsi; fakultas kedokteran universitas sumatera utara: 2017.

27.Ayzenberg Katsarava Z, Sbrowoski A, Chernysh $\mathrm{M}$ et al. Headache Attributed Burden and its Impact on Productivity and Quality of Life. Rusia; European Journal of Neurology: 2014.

28.Wang SJ, Wang P, Fuh J, Peng K. Comparisons of Disability, Quality of Life and Resource Use Between Chronic and Episodic Migraineurs. Taiwan; Clinical Journal Vol 3(3): 2013.

29.Peres M, Marusha M, Zulkerman E, Moreira-Filho J, Cavalheiro E. Potensial therapeutics use of melatonin in migraine and other headache disorder. Exper OpinInvest Drugs; 2006 ; 15(4): 367-375 